\title{
A COMPUTATIONAL AND EXPERIMENTAL COMPRESSOR DESIGN PROJECT FOR JAPANESE AND BRITISH HIGH-SCHOOL STUDENTS
}

\author{
S.D. Grimshaw, C.L. Sequeira; M. Hewkin-Smith \\ Whittle Laboratory \\ University of Cambridge \\ $1 \mathrm{JJ}$ Thomson Avenue \\ Cambridge, CB3 ODY, UK \\ Email: sdg33@cam.ac.uk
}

\section{ABSTRACT}

This paper describes an innovative, three-day, turbomachinery research project for Japanese and British high-school students. The project is structured using modern teaching theories which encourage student curiosity and creativity. The experience develops team-work and communication, and helps to break-down cultural and linguistic barriers between students from different countries and backgrounds. The approach provides a framework for other hands-on research projects which aim to inspire young students to undertake a career in engineering.

The project is part of the Clifton Scientific Trust's annual UK-Japan Young Scientist Workshop Programme. The work focuses on compressor design for jet engines and gas turbines. It includes lectures introducing students to turbomachinery concepts, a computational design study of a compressor blade section, experimental tests with a low-speed cascade and tutorials in data analysis and aerodynamic theory. The project also makes use of 3D printing technology, so that students go through the full engineering design process, from theory, through design, to practical experimental testing.

Alongside the academic aims, students learn what it is like to study engineering at university, discover how to work effectively in a multinational team, and experience a real engineering problem. Despite a lack of background in fluid dynamics and the limited time available, the lab work and end of project presentation show how far young students can be stretched when they are motivated by an interesting problem.

\footnotetext{
*Present address: Hybrid Air Vehicles Ltd, Hangar 1, Cardington Airfield, Shortstown, Bedford, MK42 0TG, UK
}

\section{INTRODUCTION}

A three-day project has been designed to provide hands-on experience of engineering research and design to high-school students from Japan and the UK. The project is held in the Whittle Laboratory at the University of Cambridge and is run by three researchers on the topic of compressor design in turbomachinery. By employing modern teaching theories, the project demonstrates the challenges, excitement and fulfillment that come with an engineering career.

75\% of UK firms with science/engineering occupations cited a shortage of skilled employees as a barrier to future growth [1], yet a difficulty in linking the theory taught in class with real applications stops many school pupils considering engineering as a career [2-4]. The facilities available to universities give them the ability to run projects for high-school students which address this problem. Several universities have designed projects, and based them in schools [5-7], but bringing students into the university environment [8-12] gives them a more immersive experience.

One reason university-based projects for high-school students are uncommon is that they require high levels of resources. When such schemes do occur, the lack of resources is often cited as a major restriction on their effectiveness [2,13]. Even successful undergraduate projects, such as Vo and Trépanier [14], acknowledge that they rely heavily on external funding and would have to make changes and restrictions if funding were removed. Compromising the approach by cutting costs, for instance using craft materials for design construction instead of realistic materials [15], reduces the relevance to real-world applications. Instead, "Students should have the opportunity to use leading edge tools and technologies to experience the excitement of ongoing research" [8]. Along with the associated financial resources, projects for high-school students often require a high staff/student ratio (e.g. 12:25 [11]) and considerable staff effort $[8-11,15,16]$. Despite these challenges, the facilities and the expertise available at the Whittle Laboratory enable this project to make use of modern research equipment at minimal expense (3D printing and staff costs 
are approximately $£ 150$ per student) while delivering a staff/student ratio of 5:12 (including language facilitators).

Turbomachinery blade design has been successfully implemented as a teaching tool for undergraduate engineering students and several lessons can be learned and applied to this project $[4,14,17-23]$. A real-time graphical user interface (GUI), which enables design changes to be visualised, keeps students interested $[4,20]$. Incremental achievements throughout the project will maintain this motivation [9-11]. Multi-disciplinary aspects of the problem should also be considered (e.g. thermal and mechanical constraints in addition to aerodynamics) to better link the project to real-world difficulties; this has been identified in both turbomachinery projects $[4,14,18,19,21]$ and other disciplines [6,9-11,24].

Due to its importance in industry, computational fluid dynamics (CFD) software is included in comprehensive turbomachinery education projects. For example Turner et al. [19], Vo and Trépanier [14] and Tomita and Barbosa [22] use commercial packages to assess design performance as part of their design iteration cycles.

The increased accessibility of 3D printing technology has allowed school and university projects to provide students the opportunity to see their work realised in physical form [9-11, 14, 24], while avoiding the expense of alternative methods such as machining [22, 23]. This allows a complete design life cycle (from theory, through analytical design, computer simulation, computer aided design (CAD), and $3 \mathrm{D}$ printing to experiment $[9-11,14])$ to be covered in a way that was not possible a few years ago $[8,18]$. Such a complete process is appreciated by students [14] and is implemented in this project.

Although open-ended projects nurture creativity and maintain motivation, projects of this nature are often too ambitious to be suitable for high-school students [2,9-11]. In addition, the mathematical level of high-school students can be constraining and result in slow progress [9-11, 15]. Denton [17] and Vo and Trépanier [14] allow design freedom, while others $[4,18-20,22]$ restrict the design process to one-dimensional parameters (e.g. reaction, blade count, stage loading). A seemingly open-ended project, which actually guides students down a prescribed path, similar to that used by Ramsden [18], is the most suitable compromise for this project.

The importance of cultural understanding (along with experience of a foreign language) is of great advantage to an engineering graduate [25]. Mund et al. [16] created an educational project with international collaboration, however, this type of project is rare. The Whittle Laboratory project appears to be unique, in the open literature, in providing such an experience for high-school students. It should also be noted that it is crucial in group-based activities to balance groups in terms of ability, gender and personality to ensure that participants feel that they are treated equally. This prevents hostility and reduced motivation and maintains a sense of fair and constructive competition [9-11].

This paper is organised as follows: the project background and aims are presented and the teaching approach is described. Details of the project activities are provided, the student feedback is discussed and the effectiveness of the project assessed.

\section{BACKGROUND}

The Clifton Scientific Trust, is an educational charity ${ }^{1}$ whose aim is to develop and implement new, effective ways of engaging school students in the application of science and engineering and to bring added meaning and motivation to their school work. It achieves this by giving students the opportunity to experience research projects of scientific exploration and application with professional scientists and engineers. Since 2001, the Clifton Scientific Trust's UK-Japan Young Scientist Workshop Programme has brought groups of approximately 50 Japanese and British high-school students together, for 16 residential week-long workshops, hosted in universities in both countries [26,27]. Each research project involves three days working in a university laboratory followed by an end-of-project team presentation of results and achievements. Teachers from the Japanese and British schools accompany their students and observe the projects, but do not take part. The schools' social demographics vary, and include, as far as the Trust's resources allow, those with students from disadvantaged backgrounds.

Schools select students whom they feel would gain the most from the Programme and who have the communication skills to share their experiences with classmates on returning to school. In addition, schools consider academic potential and motivation; many also conduct formal interviews with the students. Once chosen for the Programme, students' preferences in subject matter are used to allocate them to projects.

Since 2014, the Whittle Laboratory, part of the Department of Engineering at the University of Cambridge, has participated in the Programme by hosting a turbomachinery project. The project focuses on compressor design for jet engines and gas turbines and is devised for a team of 12 students, with equal numbers from Japan and the UK. The task is to use experimental and computational methods to improve the efficiency of a two-dimensional compressor blade section. Whilst the project introduces new concepts and ideas which are not studied in the school curriculum, an emphasis is also placed on students' personal development and enjoyment of the project. A language facilitator, who is fluent in Japanese and English, is provided by the Clifton Scientific Trust to translate where necessary and help to bridge any cultural gaps between the two nationalities.

\section{PROJECT AIMS}

The turbomachinery research carried out at the Whittle Laboratory translates well into a project for the UK-Japan Young Scientist Workshop Programme. The work has a clear connection to everyday life through air travel and power generation, it is undertaken with the close support of industrial partners and requires experimental, computational and analytical approaches which challenge students beyond their school studies. The aims for the Whittle Laboratory project are to:

1. Teach students how a jet engine provides the thrust which enables aircraft to fly and how land-based gas turbines generate electricity. This explanation will build on knowledge already gained from students' school studies;

2. Explain in more detail how a compressor in a jet engine or gas

\footnotetext{
${ }^{1}$ Registered in England \& Wales, no. 1086993.
} 
turbine works, and through practical experience show some of the key considerations for compressor design;

3. Enable students to work together on a real engineering problem that has no definitive answer;

4. Deliver the project in a way which inspires students to think about engineering as a university degree or career choice;

5. Enable students to work in a multinational team where they are encouraged to solve problems, make decisions and to support each other as they learn.

\section{TEACHING APPROACH}

To meet the project aims, the teaching approach must create a stimulating academic challenge whilst also helping students' personal development by providing an inspiring experience of real engineering research. In this section a theory of learning is considered which is used as the foundation for the teaching approach.

Kolb [28] provides a model for how students learn called the Experiential Learning Cycle. With this model Kolb proposes that the important stages of learning can be split into:

1. "Doing something", i.e. experience;

2. Observing and reflecting on that experience, getting feedback;

3. Forming concepts and generalisations, i.e. reasoning why some things went well and others went wrong;

4. Planning what to do next based on the reflections and reasoning in Stages 2 and 3;

5. Going back to the start of the cycle and repeating.

An important addition to Kolb's model was made by Morss and Murray [29] who add "Motivation" at the centre of the cycle. This is because students have to "want" to follow the cycle for it to work effectively. The model shown in Fig. 1, which combines Kolb and Morss and Murray's thinking, is well suited to this project. The Experiential Learning Cycle not only explicitly places experience within the cycle, but it also highlights that, for effective learning, students should think for themselves through reflection, reasoning and planning how to move forward. It is also not necessary for the cycle to start at the "experience" stage; students can be set off at any point in the cycle, depending on the activity. This approach has been adopted in previous engineering education projects and has been shown to improve student motivation [9-11, 14].

A student's approach to learning can vary from "surface" learning to "deep" learning depending on the context of the teaching and the type of assessment [30]. In surface learning, students memorise facts and reproduce information, but cannot necessarily make connections between related ideas. With a deep approach to learning, students attempt to link ideas, check the logic of what they are learning and make connections beyond the immediate learning material. The deep approach is the desired outcome for the Whittle Laboratory project and is stimulated by engaging, experience-based teaching and a challenging end of project assessment.

\section{PROJECT OVERVIEW}

The project has been designed and run by three researchers at the Whittle Laboratory; the laboratory-based part of the work lasts for three days (the full schedule for the project is found in the Appendix).

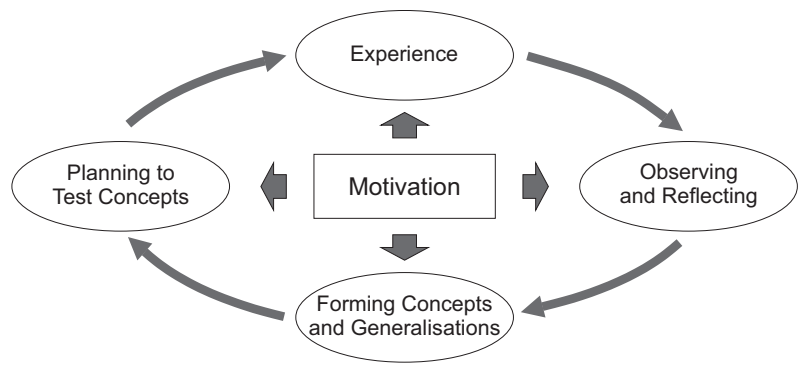

FIGURE 1: Experiential Learning Cycle (adapted from Kolb [28])

At the start of the project students receive introductory lectures which explain how jet engines and gas turbines work and which begin to develop the key ideas required to study fluid flows. These lectures set the scene and provide motivation for the project task which is to use experimental and computational methods to improve the efficiency of a two-dimensional compressor blade section.

The team of twelve participants is split into three groups of four with equal numbers of Japanese and British students in each group. During the project, groups undertake three hands-on activities, each run by one of the researchers: A computational design study, experimental tests with a compressor cascade, and data analysis and theory. The nature of the Experiential Learning Cycle allows each group to start at a different point and rotate around the activities, spending three or four hours on each, so that all students get to experience the different aspects of engineering research. Students also go around the cycle within each activity, by pausing regularly to reflect on what they have done, form new ideas and plan what to do next.

At the end of the three days the researchers facilitate a wrap-up meeting where students discuss their results, plan their team presentation and give feedback on the project. Students then have time away from the laboratory to consolidate what they have learned, and write and practice their presentation. The end of project presentation is the main method for assessing what students have learned and is delivered by the whole team to their peers (who have been participating in projects at other laboratories at the university), to their teachers and to guests from industry and academia. Further assessment of students is necessarily formative, rather than summative, and is undertaken throughout the project and in particular at the wrap-up meeting.

\section{LECTURES}

The topics encountered in this project are not usually covered until the second or third year of an engineering degree. In order to generate sustained enthusiasm, the subjects must be introduced in an accessible and enticing manner, without initially overloading students with complex information. To achieve this, the material is split into an introductory lecture on the first day and a technical lecture on the second day. This allows students some time to digest what they have learnt.

At the start of the project, an introduction is given, covering the aims, tasks, logistics and structure of the project. It does not go into technical detail, but highlights that students will undertake hands-on work. The first lecture comprises an introduction to turbomachinery. At this stage, students have already sat through a morning of talks (before arriving at the Whittle Laboratory), so the lecture is interactive and kept to around twenty minutes. Equations are avoided, with ideas 


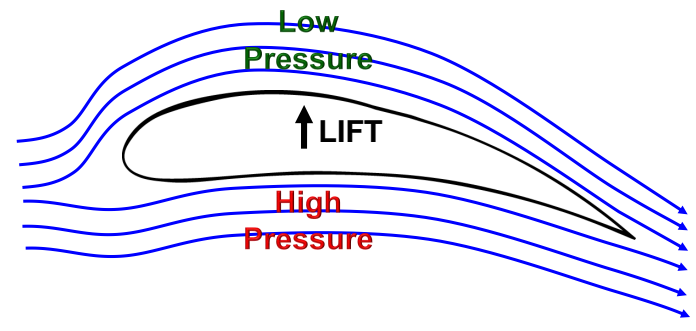

F UAMERSTYY
1) Static Pressure

2) Stagnation Pressure

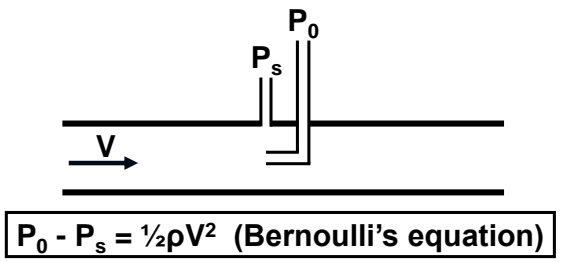

$\left(P_{s}\right)$

$\left(P_{0}\right)$

ga UAYERSTIYOI

(a)

(b)

FIGURE 2: Examples of slides from $(a)$ the introductory lecture and $(b)$ the technical lecture

introduced through simple sketches, photos, and videos, Fig. 2(a). The lecture first places the research area in context through a discussion of power generation trends and environmental concerns, before compression, combustion and expansion are introduced. The theory of wing lift is explained, along with the basic concepts of CFD. Finally, the importance of performing both experiments and CFD to validate computational results is highlighted and this is tied in with the project that students will be undertaking. A tour of the Whittle Laboratory is then used to provide real life examples of the concepts introduced.

The technical lecture is held on the second day, by which point students have had time to digest the first lecture, and ask questions to clarify misunderstandings. The basics of hydrostatics, static and stagnation pressure are discussed, before explaining how they are measured in an experiment, Fig. 2(b). Accelerating and diffusing flows are then covered, to describe in more detail how a gas turbine works. Finally, velocity triangles and non-dimensional numbers are briefly explained, in order to introduce the relative frame of reference and the concept of non-dimensional scaling. Students struggle to understand all of this at first, but they are provided with a printed handout of both lectures in advance, which they are able to annotate and refer to throughout the three days. The goal is not for the participants to understand all of the material by the end of the lecture, but by the end of the project.

\section{PROJECT ACTIVITIES \\ Computational Design Study}

The computational design study uses a custom-made compressor design tool, coupled with a commercial two-dimensional (2D) flow solver. Students begin by using the computational tool to analyse a datum design which has poor performance (loss coefficient, $\bar{\omega}=0.08)$. They then use the knowledge gained from the lectures, and group discussion, to adjust the section design to improve the compressor blade performance. The main target of the exercise is to reduce the loss coefficient as far as possible, whilst maintaining the datum flow turning of $18.2^{\circ}$ to within $\pm 1^{\circ}$.

Compressor Design Tool The design tool interface, Fig. 3, displays two plots: the first shows the distribution of blade turning between a prescribed inlet angle and an adjustable outlet angle, plus the thickness of each surface relative to this turning line; the resulting blade design is shown on the second plot. The interface allows control points for turning and thickness to be adjusted and the blade design on the right-hand plot is updated in real-time. Students are able to learn what effects changing the turning and thickness distributions have on the shape of the blade within a few minutes. The trailing edge metal angle can be adjusted using a slider and the designs can be saved, loaded and run in the flow solver, using clickable buttons. Due to mechanical constraints of the plastic used for 3D printing, the thickness of the leading and trailing edges are fixed at 5\% axial chord.

The quasi-2D coupled Euler/boundary layer solver MISES [31] is run automatically, using appropriate settings to ensure a reliable, converged solution is produced within ten seconds. Flow turning and loss coefficient are displayed in a terminal window, and MISES' inbuilt plotting software is used to investigate the results in detail; e.g. surface pressure distributions and boundary layer state, Fig. 4. The user can then return to the design interface and make further adjustments to the blade design.

Design Activities The groups of four are split into two pairs, each with one Japanese and one British student. The pairs are placed in competition with each other to produce the best design. This provides students with an additional motivation to understand the problem and use what they have learned to tackle it.

The main design aim is to reduce stagnation pressure loss coefficient whilst maintaining flow turning. Students learn that by reducing the amount of turning done near the trailing edge of the suction surface, they can delay the separation of the boundary layer and improve performance. A reduction of loss coefficient from 0.08 to 0.06 at the design incidence of $1^{\circ}$ can be achieved. Once an improvement has been made, the group holds a discussion on incidence tolerance, learning how a change of flow angle results from a change in operating conditions. The pairs then run their improved design at a range of incidences, before plotting the results compared to the datum performance, Fig. 5. The implications of the resulting changes are examined; for example, discussing whether the benefit of a reduction in design point loss coefficient outweighs a reduction in incidence range. 


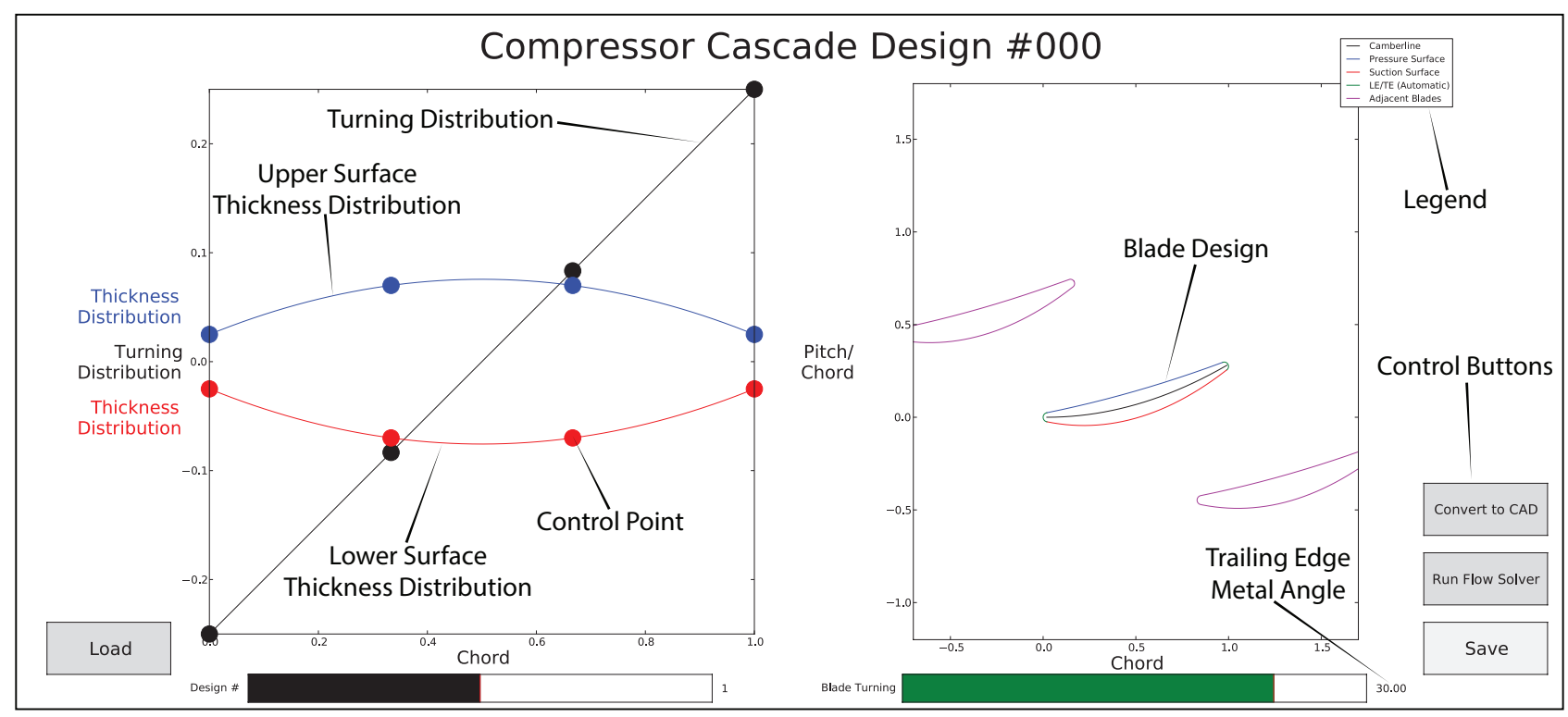

FIGURE 3: Compressor design tool interface
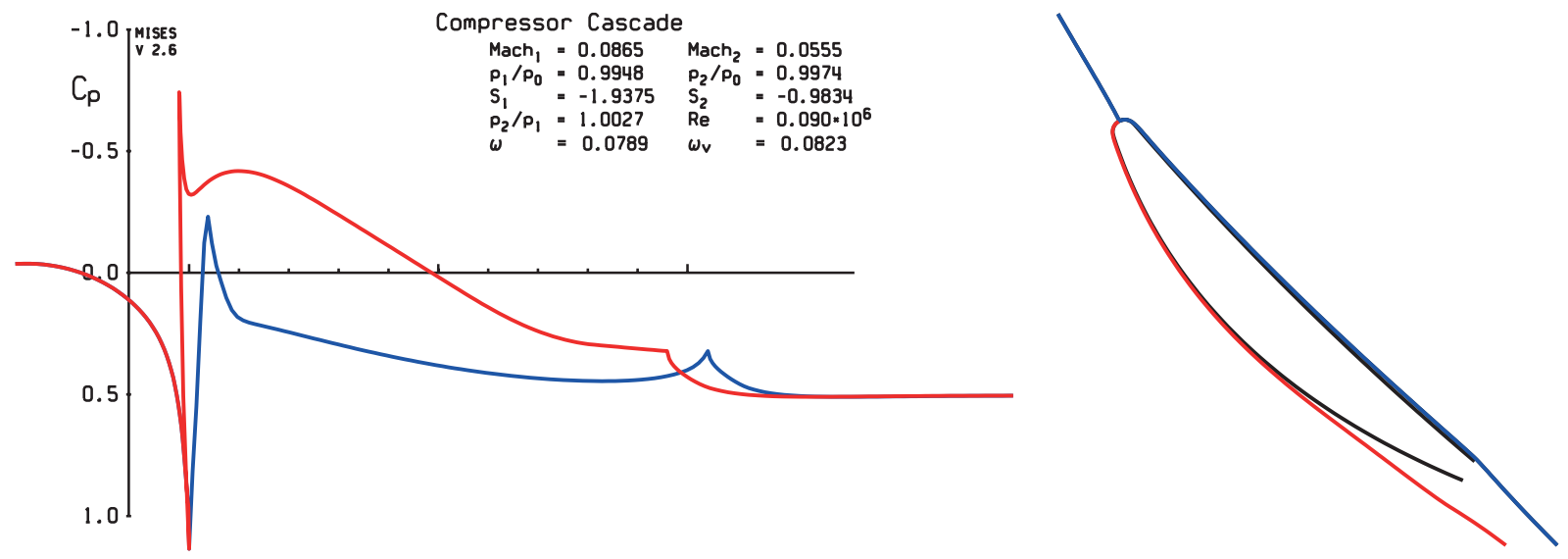

FIGURE 4: Blade surface static-to-static pressure coefficient distribution $\left(C_{p}\right)$ and boundary layer results (adapted from MISES)
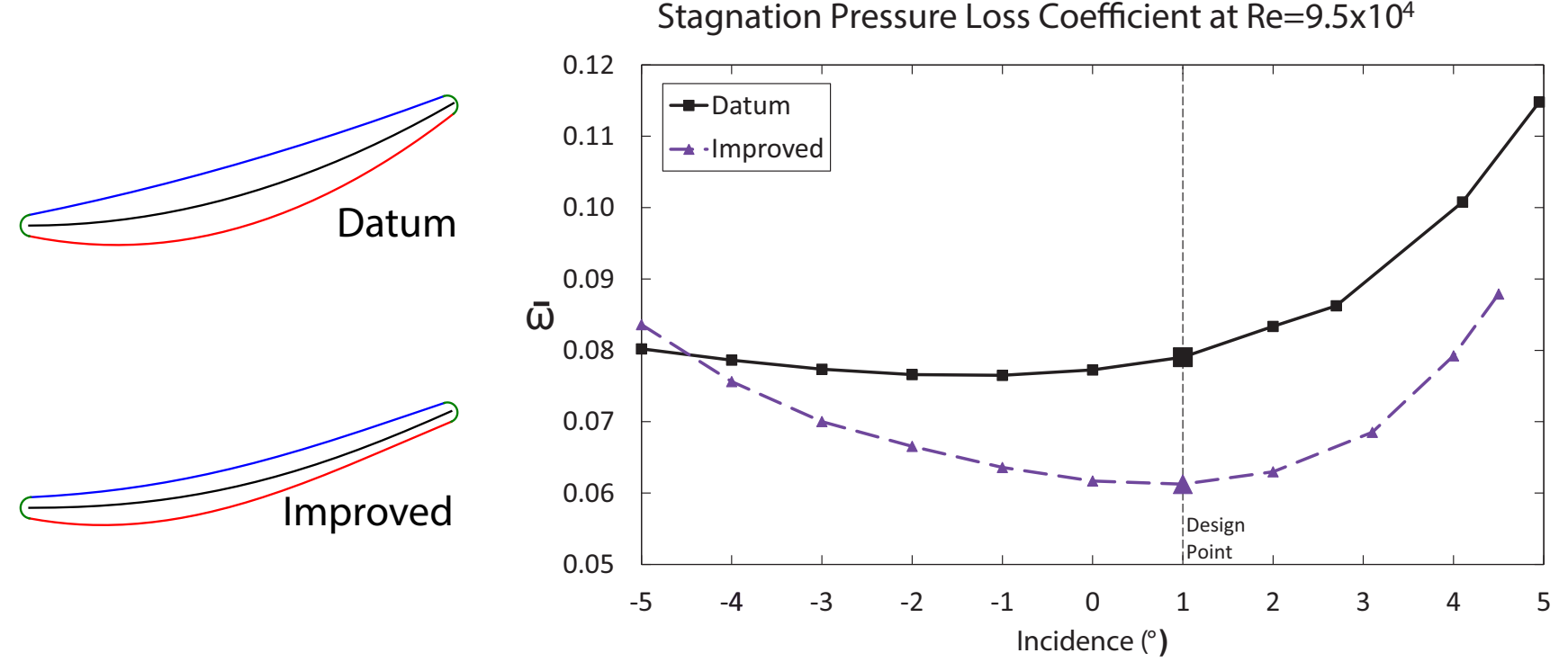

FIGURE 5: Datum and improved designs from the compressor design tool and the resulting plot of stagnation pressure loss coefficient $(\bar{\omega})$ against incidence. 

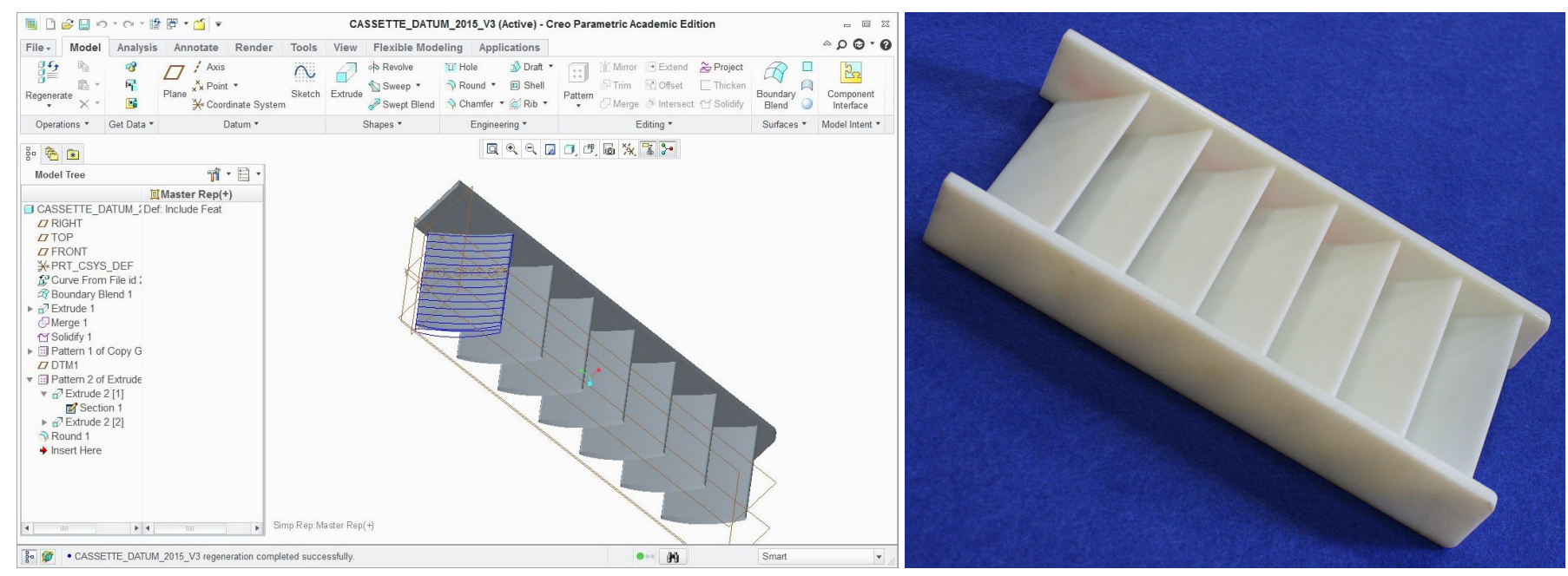

FIGURE 6: Modelling the compressor cascade cassette using CAD and a 3D printed cassette.

The better of the two pairs' designs is then prepared for a 3D printer using commercial CAD software, Fig. 6. Due to time constraints, this is undertaken as a group activity, with one student in control of the computer and the researcher instructing them on how to create the CAD model. This part of the project is more of an interactive demonstration than a learning exercise, but it allows the full design path from theory to a physical object to be completed. All groups gather at the end of the second day to see the 3D printing in progress and discuss how it works and what can be achieved with such technology. The opportunity for students to see their work take physical form is a key attribute of this project and links the computational work with the experiment.

The three groups each undertake the computational design study at different stages of the project. To make sure each student can make a contribution to the progress of the overall project, the design activity is modified for each group. The first group undertake the activity as above, and then must decide which pair's design is best; this is the design that is $3 \mathrm{D}$ printed. The second group consider the effect of Reynolds number on performance. They carry out the same blade design activity, at an engine appropriate Reynolds number $\left(5.5 \times 10^{5}\right)$, rather than the low Reynolds number of the experimental rig used by the first group $\left(9.5 \times 10^{4}\right)$. The discrepancy in results (a greater reduction in loss from 0.08 to 0.05 ) is used to highlight one of the real-world problems associated with experiments: the importance of experimental matching with real conditions. The final group considers the effects of mechanical constraints by reducing the minimum thickness criteria imposed on the leading and trailing edges. They then see how much further improvement in performance can be achieved. The improvement possible (a reduction of loss from 0.08 to 0.05 at the lower Reynolds number) demonstrates how engineers are not always able to achieve the best design from a certain perspective (aerodynamic in this case) because other constraints are the limiting factor (thermal/structural properties).

\section{Experimental Tests}

The experimental tests require students to measure the stagnation pressure loss and flow angle downstream of the compressor blade and to use flow visualisation paint to investigate the state of the boundary layer on the blade suction surface.

Experimental Equipment The researcher gives a safety briefing and explains how the experimental equipment works. A detailed lab handout is provided for students to refer to. Where possible, students are asked questions and encouraged to work things out for themselves. For example, students are asked to make the link between Pitot and static pressure probes and how a three-hole probe can be used to measure the flow angle and stagnation pressure downstream of the compressor blade.

This approach allows students to understand the use of the wind tunnel and its throttle, the barometer, differential pressure manometers and thermocouples, the upstream Pitot and static pressure probes and the three-hole probe. They are also shown how to mix the flow visualisation paint and apply it to the blades. The experimental test facility used by students is show in Fig 7.

Experimental Measurements Wake traverse measurements are performed first. In order to calculate the flow angle and stagnation pressure loss coefficient downstream of the blades, the three-hole probe is traversed across one pitch of the compressor cascade blades and students record: traverse position, three-hole probe nulled angle (the angle at which the side holes on the probe have equal pressure), the difference between upstream stagnation pressure and static pressure, and the difference between upstream stagnation pressure and downstream stagnation pressure. The experimental equipment is not automated so students have to work out an efficient process to take these measurements. This requires the group to work together and tests the communication skills of the Japanese and British students. Students normally refine this process within a few minutes, with little help from the researcher.

Each group has a different task. The first group tests the datum blade design, the second group tests the datum blade design with a 


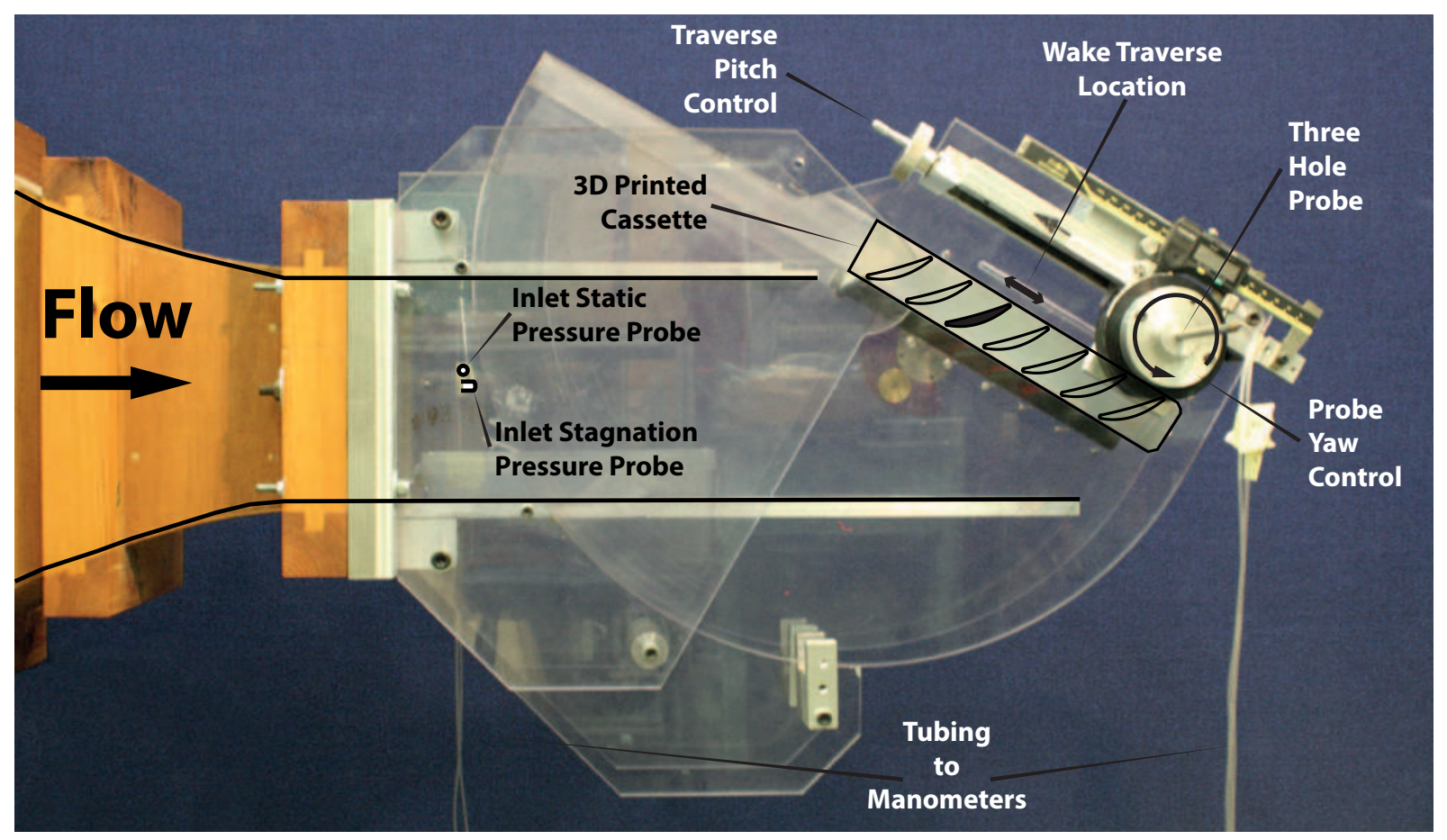

FIGURE 7: Experimental Test Facility

boundary layer trip at 5\% chord on the suction surface, and the third group tests the 3D printed improved design from the computational design study.

Several issues with the experimental setup, equipment and process for the wake traverse are left for students to identify. For example, they are not told how many traverse points to use. To answer this question students are asked to draw on their previous experience, i.e. how do they decide how much data to take in school science experiments? What factors effect and constrain this? Through this thinking one group decided to do an initial, coarse traverse of just 6 points across the blade pitch. A traverse of a further 10 points was then performed in the region where the pressures and flow angles vary, therefore giving a finer resolution of the wake. Another practical issue is how to get the viscosity of the flow visualisation paint correct so that the paint flows, but does not run too much after the tunnel is turned off. Students have to use their own judgment to mix the silicon solution and paint pigment, but after several attempts are able to produce a mixture that works well.

Having run the flow visualisation test, the researcher facilitates a discussion about what students have observed. The way that attached and separated boundary layers affect the paint flow on the blade surface is discussed. One group of students also noticed the pattern caused by the endwall corner separation and this led to a discussion of three-dimensional flows in turbomachinery. The results of the flow visualisation tests are recorded by photographing the painted blades in a dark room with UV light and a long exposure.

\section{Data Analysis and Theory}

The data analysis and theory activity draws on the University of Cambridge small-group tutorial teaching style. Students consolidate their learning from the computational and experimental activities and use their understanding to critically examine their results. This exercise closes the Experiental Learning Cycle loop for the project by requiring students to reflect on and reconsider the design cycle they have applied.

There are three main components to this activity. First, the researcher discusses the key flow physics and methods underpinning compressor design, with a focus on boundary layers, flow separation, non-dimensional variables, experimental techniques and computational design. This discussion is driven by asking questions, to which students are encouraged to answer by applying what they have learned from the other activities. The outcome of this discussion is that students are able to understand and explain the flow visualisation patterns shown in Fig. 8. The flow on the datum blade provides good examples of both 1) attached flow, where the air flows along the surface removing most of the paint, and 2) separated flow, where the low velocity close to the surface causes the paint to accumulate. The case with a boundary layer trip exhibits a small separation bubble immediately after the trip. The flow then reattaches with a turbulent boundary layer -which students learn is more resistant to separation than a laminar boundary layer- and hence stays attached to the rest of the blade surface. Students are able to identify the attached and separated regions of flow on the improved blade design and observe that the separation size is reduced compared to the datum.

Second, students are required to analyse the traverse results and produce four outputs: pitchwise plots and area-averaged values of loss coefficient and yaw angle. Figure 8 shows the students' plot of loss coefficient against pitch for the three cases. Through further discussion, and questioning, students are able to connect the traverse results with the flow visualisation photos. The datum blade design has an area-averaged loss coefficient of 0.177. Although adding the trip increased the peak loss, students observe that the loss coefficient reduces to 0.155 , because the width of the wake is reduced. 


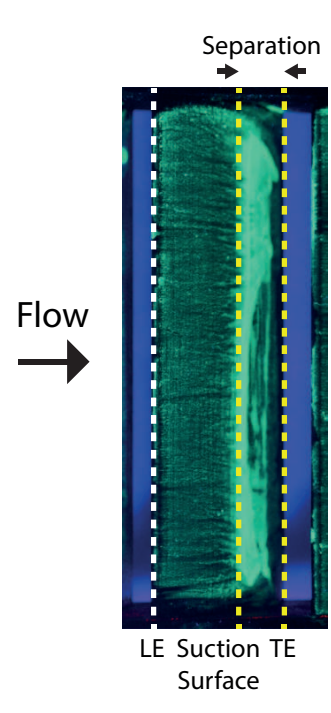

Datum
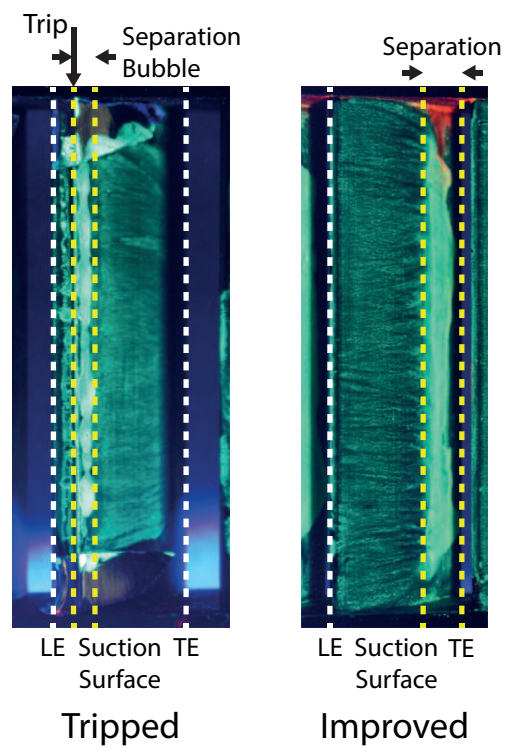

Wake Traverse Measurements

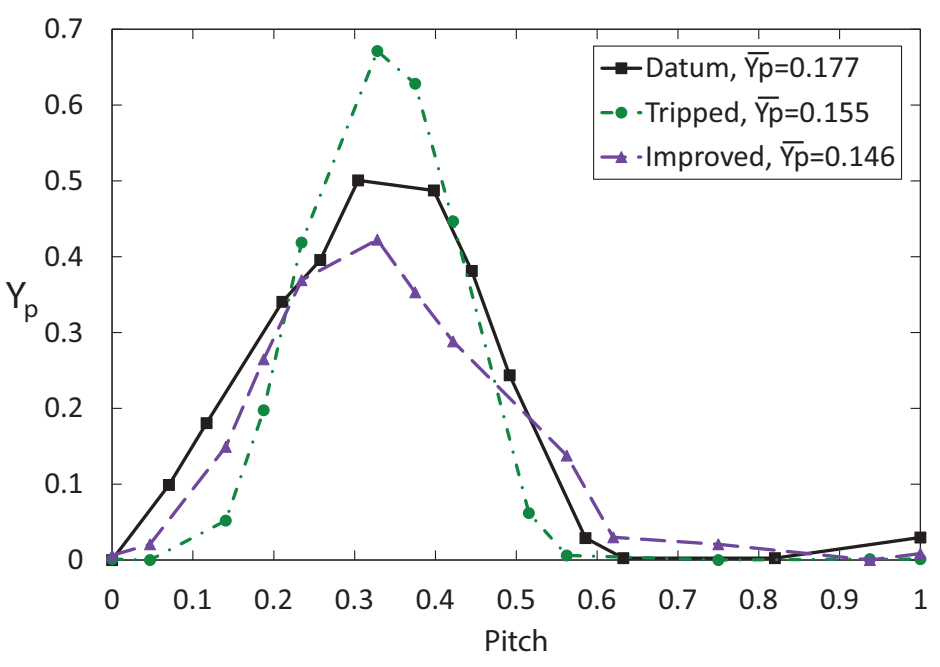

FIGURE 8: Suction surface flow visualisation and comparison of stagnation pressure loss coefficient $\left(Y_{p}\right)$ wake traverse results for datum, tripped and improved blade designs.

The reduction in wake width is then related to the removal of the separated region, as seen in the flow visualisation. The improved blade design has the lowest area-averaged loss coefficient of 0.146 , an $18 \%$ improvement over the datum design. Students are able to explain that although the size of the separation (and hence the width of the wake) is not changed significantly, the peak loss is reduced.

Finally, students compare the area-averaged values of loss coefficient and yaw angle with computational predictions. This introduces the idea of data validation, and computational and experimental results which do not match. The loss coefficient data should be mass averaged, but area averaging is used since velocity measurements are not available downstream of the blade row. The rationales behind different averaging techniques are explained and prove to be one of the harder concepts for students to comprehend.

Each group undertakes this activity at a different point in the project, so the researcher must adjust the tone of the discussion to account for the level of experience already achieved. The first group spends more time understanding the principles of computational design, and is shown examples of the experimental equipment they will encounter later on. The data they analyse is a sample dataset from the facilitator. The second group analyses the experimental data they have produced, and are pressed to explore how it would change if the blade design was improved. This prepares them for the computational design exercise. The third group compares the two sets of experimental data produced by students, and explores the change in results in the context of the design variations.

This activity is considered the hardest by most students. Nevertheless, they find it rewarding once they begin to understand how the different design considerations, CFD predictions and experimental measurements fit together.

\section{Wrap-Up Meeting}

The Wrap-up Meeting is held at the end of the project and involves all students, language facilitators and researchers. The primary aim is to consolidate the ideas learned to prepare students for their final presentation. This meeting is also used as a platform to engage students' opinions on how the project was run and how it could be improved.

The meeting is structured around four exercises. In the first, students take turns to identify something they have learned, with each required to state something new until the team has nothing left to say. Each idea is recorded in a "mind-map" on a board. Students are encouraged to identify technical and non-technical factors, including the theory they have learned, and the importance of experiments, computations, analysis and communication in the engineering design process. During the exercise, students are given the opportunity to clarify technical misunderstandings and to ask further questions having completed the entire project. Students, with guidance from the researchers, then identify the most important learning outcomes from the mind-map; this forms the basis of their presentation.

The second exercise is a discussion, led by the researchers, about how to deliver a cogent and successful presentation. The researchers emphasise the need for clear slides, with minimal text, and to present the most important ideas in a manner that flows in a "story". Examples of good and bad slides are used to demonstrate these points.

In the third exercise, students are required to use their key findings to structure a presentation under the guidance of the researchers. Their task is to list slide titles based on their findings, and order them such that they tell a coherent and interesting story in six parts. The researchers then arrange students into six pairs, each with one Japanese and one British student. Each pair then volunteers for a different section of the presentation. The details of the sections are left for students to work on.

The final exercise requires each student, in turn, to identify what they enjoyed and did not enjoy about the project. If they need to, Japanese students are encouraged to speak in Japanese, via the language facilitator, to ensure that they can fully express their views. 


\section{Student Presentations}

The main assessment of students is a summary presentation of the work done in the project. The presentation session is held in a university lecture theatre and the audience includes other student participants of the Programme, students' teachers, researchers who have led projects, Clifton Scientific Trust organisers, and invited guests from industry partners who support the Programme.

After three days at the Whittle Laboratory, students have a day to relax and explore Cambridge with the Trust organisers. They then have an evening and a morning to prepare their presentation. Having outlined the key ideas and identified who will present each one in the wrap-up meeting, students must prepare and practice the content of the slides. The presentations are 25 minutes long, giving each pair around 4 minutes to present their section.

It should be emphasised that preparation of the presentation is done entirely independently of the researchers. It is a significant challenge for students to combine the ideas identified at the wrap-up meeting with everything they have learned during the project to produce a good presentation. This is one of the most difficult parts of the project, but a sense of pride in their work and competition with the other teams drives students to work hard in preparing for the presentation.

The result of this work is a successful, clear and concise presentation which is given with enthusiasm. The technical content of the presentation is impressive and includes the results presented in this paper. This demonstrates how much high-school students are able to understand about aerodynamic research in just three days. Students present difficult ideas through simple analogies; for example, explaining blade wakes by showing a picture of the wake of a motor boat, or explaining the theory of boundary layer transition by sketching a straight line that turns wiggly. Students recognise their own achievement and are excited and proud to have been able to deliver such a well-received presentation. The presentation is particularly testing for Japanese students as they are required to present in English. However, through the support of their colleagues and in some cases with the use of cue cards, all students are able to present the ideas well.

After the presentation, questions are taken from the audience. These include technical questions about project work, and questions about the cultural and team work aspects of the project. At this stage, as responses cannot be prepared, the Japanese students may answer through a facilitator, although many choose to reply in both languages.

\section{STUDENT FEEDBACK}

The discussion in the wrap-up meeting is supplemented by students' written feedback on what they enjoyed and did not enjoy about the project, what was the most important thing they learned, and what they found hardest to understand. Without any further prompting, students reflect on their academic and cultural experiences and their responses vary. Some examples of responses are given here:

- "What I enjoyed most about the week was when we designed the improved blade using CAD because we were able to apply what we had learned and actually design something that could be used."

- "I was able to cooperate with the members of the project team, and doing the final presentation successfully improved my self-confidence"
- "I realised students from the UK like science as much as I do, look forward to communicating with Japanese students just like I do, so there's no difference between us, we are high school students the same as each other."

- "I learned that understanding and respecting each other's culture is one of the most important things for surviving in the global community. By the last day we were part of a team regardless of whether we were a Japanese or UK student."

- "The hardest part of the project for me was some of the theory in the lectures as it was quite complex and hard for me to visualise, which could be frustrating at times, but as the week went on and we discussed it more my understanding increased."

- "The lecture on the first day was a little hard for me but by doing experiments and talking with team members I got to understand. In the discussions we talked about the results, and I realised that we have to consider results from many points of view."

- "Through a lot of people's help I was able to understand the experiment. On reflection whilst the contents of the project were difficult, by studying a little about it myself, I was able to understand it much better."

- "I learned the importance of predicting exactly, doing experiments accurately, analysing the results over and over and not leaving the wrong things as they are."

- "During the preparation for the presentation we also talked a lot about how we can make a simple, easy to understand, interesting and cool presentation. I found some important differences between English presentations and Japanese and we realised that what is important is not the mass of information but simple, clear presentation of the main ideas."

- "The most important thing I learned was what engineering is really about. I had never considered it as a possible career path before, but having enjoyed the project so much, I know that it is what I want to do in the future."

The student feedback and the end-of-project presentation assessment demonstrate that the project aims are being met. The comments above show that students learned through doing, reflecting and discussing, forming new concepts and then thinking about what to do next; this reflects the "Experiential Learning Cycle". This shows that the teaching approach motivates students and encourages them to work hard and stretch themselves. Students are conscious of the challenges of working with people from another country and with a different language. This type of project provides shared experiences and goals, and is able to break down cultural differences and language barriers.

\section{CONCLUSIONS}

This paper describes a turbomachinery research project, run for 12 high-school students from Japan and the UK over three days, with the aims of teaching the principles of axial compressor design and of giving an inspirational experience of engineering research. The complete engineering design process, including theory, computational design, experimental testing and data analysis, is covered. Students are able to see their own designs produced and tested in a university research facility through use of 3D printing technology. From the experience of running this project, the following conclusions are drawn: 
1. Linking the subjects taught in schools with current engineering research encourages high-school students to think about careers in engineering.

2. Constraining the project to pre-determined activities, but giving students the freedom to decide the approach taken within these, ensures the learning outcomes are achieved whilst generating student interest.

3. Basing the project around the Experiential Learning Cycle provides a structure through which discrete activities, undertaken at different stages of the project, can link together to convey the subject matter.

4. Simplifying the material initially, allowing time to digest new ideas, then concentrating on simple, yet core, mathematical and physical principles, with discussion throughout, allows students to understand complex concepts, in depth, in just a few days.

5. Competing for the best blade design, with the prospect of having it 3D printed and tested in the experimental facility, drives students to work hard to understand the problem and apply their learning to the computational design study.

6. Looking at the same theories and ideas from three different perspectives (experimental, computational, theoretical) reinforces the concepts at each stage, ensuring a deeper understanding of the problem by the end of the project.

7. Focusing students' thoughts onto the key outcomes of their work allows them to produce a coherent and concise presentation without assistance from the researchers.

8. Working in a multinational team breaks down language barriers and broadens students' ideas of other cultures, preparing them for the multicultural, multinational and multilingual field of engineering.

\section{NOMENCLATURE}

$C$ Blade Chord

$C_{p} \quad$ Static-to-Static Pressure Coefficient $=\frac{p-p_{1}}{\frac{1}{2} \rho_{1} V_{1}^{2}}$

$C A D \quad$ Computer Aided Design

$C F D \quad$ Computational Fluid Dynamics

Mach $_{1} \quad$ Inlet Mach Number

Mach $_{2}$ Exit Mach Number

$p_{1} \quad$ Inlet Static Pressure

$p_{2} \quad$ Exit Static Pressure

$p_{o 1} \quad$ Inlet Stagnation Pressure

$p_{o 2} \quad$ Exit Stagnation Pressure

$p_{o 2}^{i s e n} \quad$ Isentropic Exit Stagnation Pressure

$\bar{p}_{o 2} \quad$ Mixed-Out Exit Stagnation Pressure

Re Reynolds Number

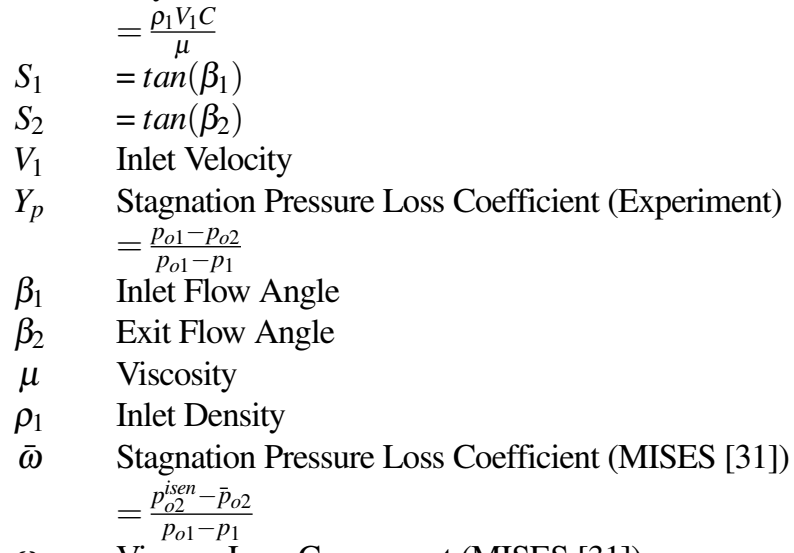

$\omega_{v} \quad$ Viscous Loss Component (MISES [31])

\section{APPENDIX- PROJECT SCHEDULE}

\begin{tabular}{|c|c|c|c|c|c|c|c|c|c|c|c|}
\hline & \multicolumn{3}{|c|}{ Day 1} & \multicolumn{3}{|c|}{ Day 2} & \multicolumn{3}{|c|}{ Day 3} & Day 4 & Day 5 \\
\hline 09:00 - 10:30 & \multirow{4}{*}{\multicolumn{3}{|c|}{$\begin{array}{l}\text { Introductions and Lunch with } \\
\text { Clifton Scientific Trust }\end{array}$}} & \multicolumn{3}{|c|}{ Technical Lecture } & $\begin{array}{c}\text { Group A } \\
\text { Exp. }\end{array}$ & $\begin{array}{l}\text { Group B } \\
\text { Analysis }\end{array}$ & $\begin{array}{c}\text { Group C } \\
\text { Design }\end{array}$ & \multirow{7}{*}{$\begin{array}{l}\text { Assimiliation } \\
\text { Time } \\
\text { (Excursions } \\
\text { Organised by } \\
\text { Clifton } \\
\text { Scientific Trust) }\end{array}$} & \multirow{3}{*}{$\begin{array}{l}\text { Presentation Preparation } \\
\text { (Independent of Whittle } \\
\text { Laboratory Researchers) }\end{array}$} \\
\hline 10:30 - 11:00 & & & & \multicolumn{3}{|c|}{ Break } & \multicolumn{3}{|c|}{ Break } & & \\
\hline $11: 00-12: 30$ & & & & $\begin{array}{l}\text { Group A } \\
\text { Design }\end{array}$ & $\begin{array}{l}\text { Group B } \\
\text { Exp. }\end{array}$ & $\begin{array}{l}\text { Group C } \\
\text { Analysis }\end{array}$ & $\begin{array}{l}\text { Group A } \\
\text { Analysis }\end{array}$ & $\begin{array}{l}\text { Group B } \\
\text { Design }\end{array}$ & $\begin{array}{l}\text { Group C } \\
\text { Exp. }\end{array}$ & & \\
\hline $12: 30-13: 30$ & & & & \multicolumn{3}{|c|}{ Lunch } & \multicolumn{3}{|c|}{ Lunch } & & \\
\hline $13: 30-15: 00$ & \multicolumn{3}{|c|}{$\begin{array}{l}\text { Introductory Lecture and } \\
\text { Laboratory Tour }\end{array}$} & $\begin{array}{l}\text { Group A } \\
\text { Design }\end{array}$ & $\begin{array}{l}\text { Group B } \\
\text { Exp. }\end{array}$ & $\begin{array}{l}\text { Group C } \\
\text { Analysis }\end{array}$ & $\begin{array}{l}\text { Group A } \\
\text { Analysis }\end{array}$ & $\begin{array}{l}\text { Group B } \\
\text { Design }\end{array}$ & $\begin{array}{l}\text { Group C } \\
\text { Exp. }\end{array}$ & & Presentation Session \\
\hline $15: 00-15: 30$ & \multicolumn{3}{|c|}{ Break } & \multicolumn{3}{|c|}{ Break } & \multicolumn{3}{|c|}{ Break } & & \multirow[b]{2}{*}{ End of Project } \\
\hline $15: 30-17: 00$ & $\begin{array}{l}\text { Group A } \\
\text { Design }\end{array}$ & $\begin{array}{l}\text { Group B } \\
\text { Exp. }\end{array}$ & $\begin{array}{l}\text { Group C } \\
\text { Analysis }\end{array}$ & $\begin{array}{l}\text { Group A } \\
\text { Exp. }\end{array}$ & $\begin{array}{l}\text { Group B } \\
\text { Analysis }\end{array}$ & $\begin{array}{l}\text { Group C } \\
\text { Design }\end{array}$ & \multicolumn{3}{|c|}{ Wrap-Up Meeting } & & \\
\hline
\end{tabular}




\section{ACKNOWLEDGEMENTS}

The authors gratefully acknowledge the Clifton Scientific Trust for its organisation of the UK-Japan Young Scientists Workshop Programme. Particular thanks go to Dr Eric Albone (eric.albone@cliftonscientific.org) for his orchestration of the Programme and support of the authors in running the project and writing this paper. In addition, the project was greatly enhanced through the hard work of the language facilitators: Anna Buda and Thomas Adams (2015) and Dr Marie Buda (2014). The authors would also like to thank Dr Ivor Day and Dr Cesare Hall for taking the time to deliver the technical lecture at the start of the project and Dr Graham Pullan for providing the Python code upon which the interface to the compressor design tool was based. We are also grateful to the other members of the Whittle Laboratory who have provided assistance in running the project, especially Dr Richard Jefferson-Loveday, Chris Clark, Nishad Sohoni, Ho-On To, Stefan Waterson and John Saunders. Finally, thanks go to all the students who have participated in the project.

\section{REFERENCES}

[1] Adonis, L., 2014. "Mending the fractured economy: Smarter state, better jobs". Adonis Review.

[2] Chin, J., Zeid, I., Duggan, C., and Kamarthi, S., 2012. "Why engineering-based learning can revolutionize stem teaching in high schools". In ASME 2012 International Mechanical Engineering Congress and Exposition, American Society of Mechanical Engineers, pp. 383-393.

[3] Zeid, A., Kamarthi, S., Duggan, C., and Chin, J., 2011. "Capsule: An innovative capstone-based pedagogical approach to engage high school students in stem learning”. In ASME 2011 International Mechanical Engineering Congress and Exposition, American Society of Mechanical Engineers, pp. 305-314.

[4] Gutzwiller, D. P., Turner, M. G., and Downing, M. J., 2009. "Educational software for blade and disk design". In ASME Turbo Expo 2009: Power for Land, Sea, and Air, American Society of Mechanical Engineers, pp. 827-838.

[5] Billiar, K. L., Belisle, R., Cezar, T., Fusco, M., Gray, C., Oliva, T., Tate, V. L., Hubelbank, J., and Camesano, T. A., 2009. "K12 outreach: Using biomechanical engineering design projects to teach difficult stem concepts to middle school students". In ASME 2009 Summer Bioengineering Conference, American Society of Mechanical Engineers, pp. 477-478.

[6] Bailey, M. B., and DeBartolo, E., 2007. "Heat transfer traveling engineering activity kit: Designed by engineering students for middle school students". In ASME 2007 International Mechanical Engineering Congress and Exposition, American Society of Mechanical Engineers, pp. 381-392.

[7] Cavalli, M., Carlson, N., and Compton, P., 2007. "Design collaboration between high school, on-campus, and distance engineering students". In ASME 2007 International Mechanical Engineering Congress and Exposition, American Society of Mechanical Engineers, pp. 481-485.

[8] English, K. W., Hulme, K. F., and Lewis, K. E., 2008. "Engaging high school women in engineering design using cyberinfrastructure". In ASME 2008 International Design Engineering Technical Conferences and Computers and
Information in Engineering Conference, American Society of Mechanical Engineers, pp. 543-554.

[9] Cappelleri, D. J., Keller, J. F., Kientz, T., Szczesniak, P., and Kumar, V., 2007. "Saast robotics: An intensive three week robotics program for high school students". In ASME 2007 International Design Engineering Technical Conferences and Computers and Information in Engineering Conference, American Society of Mechanical Engineers, pp. 587-595.

[10] Keller, J., Cappelleri, D., Kientz, T., Ayanian, N., White, P., and Kumar, V., 2008. "Capturing the interest of future engineers the development of an intensive three-week summer academy in robotics for high school students". In Proc. of the ASEE Mid-Atlantic Section Conference.

[11] Ayanian, N., Keller, J., Cappelleri, D., and Kumar, V., 2010. "Development of a successful open-ended robotics design course at the high school level". Comput. Educ. J, 1(3), pp. 21-31.

[12] Sadeghipour, S. M., and Asheghi, M., 2003. "Nano-scale heat transfer education at carnegie mellon university: Programs for mechanical engineering and high school students". In ASME 2003 International Mechanical Engineering Congress and Exposition, American Society of Mechanical Engineers, pp. 393-397.

[13] Conley, C. H., Ressler, S. J., Lenox, T. A., and Samples, J. W., 2000. "Teaching teachers to teach engineering". Journal of Engineering Education, 89(1), pp. 31-38.

[14] Vo, H. D., and Trépanier, J.-Y., 2015. "Undergraduate project in compressor rig design, fabrication and testing for complete engineering training”. In ASME Turbo Expo 2015: Turbine Technical Conference and Exposition, American Society of Mechanical Engineers, pp. V006T07A002-V006T07A002.

[15] Valley, K. J., Nguyen, L. Q., Rodela, A., and Houchens, B. C., 2012. "Learning outcomes from design of wind turbines carried out by underserved high school mentees participating in dream". In ASME 2012 International Mechanical Engineering Congress and Exposition, American Society of Mechanical Engineers, pp. 411-420.

[16] Mund, F. C., Kalfas, A. I., Abhari, R. S., Turcan, Y., Hourmouziadis, J., Trébinjac, I., and Vouillarmet, A., 2003. “A multi-component and multi-disciplinary student design project within an international academic and industrial collaboration". In ASME Turbo Expo 2003, collocated with the 2003 International Joint Power Generation Conference, American Society of Mechanical Engineers, pp. 723-732.

[17] Denton, J., 1996. "The turboexpander: A design, make and test student project”. In ASME 1996 International Gas Turbine and Aeroengine Congress and Exhibition, American Society of Mechanical Engineers, pp. V005T16A004-V005T16A004.

[18] Ramsden, K., 1999. "An interactive methodology for axial compressor design teaching". In ASME 1999 International Gas Turbine and Aeroengine Congress and Exhibition, American Society of Mechanical Engineers, pp. V004T05A005-V004T05A005.

[19] Turner, M. G., Merchant, A., and Bruna, D., 2011. "A turbomachinery design tool for teaching design concepts for axial-flow fans, compressors, and turbines". Journal of Turbomachinery, 133(3), p. 031017.

[20] Marineau, E. C., and Reggio, M., 2007. “A matlab toolbox for 
the intuitive knowledge of turbomachinery". In ASME Turbo Expo 2007: Power for Land, Sea, and Air, American Society of Mechanical Engineers, pp. 527-533.

[21] Hourmouziadis, J., Schroeder, N., Biegi, K., Schmidt, K.-J., Servaty, S., and Gärtner, W., 2000. "A multimedia aeroengine design course with industry support". In ASME Turbo Expo 2000: Power for Land, Sea, and Air, American Society of Mechanical Engineers, pp. V004T05A005-V004T05A005.

[22] Tomita, J. T., and Barbosa, J. R., 2012. "Numerical tools for high performance axial compressor design for teaching purpose". In ASME Turbo Expo 2012: Turbine Technical Conference and Exposition, American Society of Mechanical Engineers, pp. 489-499.

[23] Tomita, J. T., Barbosa, J. R., and Bringhenti, C., 2014. "Experiences on project-based-classes for turbomachine design in an aerospace engineering undergraduate program". In ASME Turbo Expo 2014: Turbine Technical Conference and Exposition, American Society of Mechanical Engineers, pp. V006T08A007-V006T08A007.

[24] Metzler, T., and Shea, K., 2011. "Lessons learned from a projectbased learning approach for teaching new cognitive product development to multi-disciplinary student teams". In ASME 2011 International Design Engineering Technical Conferences and Computers and Information in Engineering Conference, American Society of Mechanical Engineers, pp. 589-598.

[25] Howard, J. H., and Ratz, H. C., 1997. "The international engineering student exchange program at the university of waterloo". In ASME 1997 International Gas Turbine and Aeroengine Congress and Exhibition, American Society of Mechanical Engineers, pp. V004T16A004-V004T16A004.

[26] Albone, E., and Okano, T., 2012. "The uk-japan young scientist workshop programme; learning lessons for education?". Education in Science, 250, pp. 18-19.

[27] Wortley, K., 2014. Inspired minds. How science helps create global leaders. BCCJ Acumen, September.

[28] Kolb, D. A., 2014. Experiential learning: Experience as the source of learning and development. Pearson Education.

[29] Morss, K., and Murray, R., 2005. Teaching at university: A guide for postgraduates and researchers. Sage.

[30] Ramsden, P., 2003. Learning to teach in higher education. Routledge.

[31] Drela, M., 1985. "Two-dimensional transonic aerodynamic design and analysis using the euler equations". $\mathrm{PhD}$ thesis, Massachusetts Institute of Technology. 